\title{
'Cookies on a tray': Superselective Hierarchical Microstructured Poly(L-lactide) Surface As a Decoy For Cells
}

\author{
Bartlomiej Kryszak $^{1 *}$, Konrad Szustakiewicz ${ }^{1^{*}}$, Paulina Dzienny ${ }^{2}$, Adam Junka ${ }^{3}$, \\ Justyna Paleczny ${ }^{3}$, Patrycja Szymczyk-Ziółkowska ${ }^{4}$, Viktoria Hoppe ${ }^{4}$, Michal \\ Grzymajło $^{1}$, Arkadiusz Antończak ${ }^{2}$ \\ ${ }^{1}$ Department of Polymer Engineering and Technology, Faculty of Chemistry, Wroctaw University of \\ Science and Technology (WUST), Wyb. Wyspiańskiego 27, 50-370 Wrockaw, Poland, \\ *corresponding. authors: bartlomiej.kryszak@pwr.edu.pl,konrad.szustakiewicz@pwr.edu.pl \\ ${ }^{2}$ Laser and Fiber Electronics Group, Faculty of Electrical Engineering, WUST, Poland \\ ${ }^{3}$ Department of Pharmaceutical Microbiology and Parasitology, Wrockaw Medical University, Borowska \\ 211A, 50-556 Wroctaw, Poland \\ ${ }^{4}$ Center for Advanced Manufacturing Technologies, Faculty of Mechanical Engineering, WUST, Poland.
}

\section{ABSTRACT}

In this research we developed a micro-sized hierarchical structures on a poly(L-lactide) (PLLA) surface. The obtained structures consist of round-shaped protrusions with a diameter of $\sim 20 \mu \mathrm{m}$, a height of $\sim 3 \mu \mathrm{m}$, and the distance between them $\sim 30 \mu \mathrm{m}$. We explored the effect of structuring PLLA to design a non-cytotoxic material with increased roughness to encourage cells to settle on the surface. The PLLA foils were prepared using the casting melt extrusion technique and were modified using ultra-short pulse irradiation - a femtosecond laser operating at $\lambda=1030 \mathrm{~nm}$. A hierarchical microstructure was obtained resembling 'cookies on a tray'. The cellular response of fibro- and osteoblasts cell lines was investigated. The conducted research has shown that the laser-modified surface is more conducive to cell adhesion and growth (compared to unmodified surface) to such an extent that allows the formation of highly-selectively patterns consisting of living cells. In contrast to eukaryotic cells, the pathogenic bacteria Staphylococcus aureus covered modified and unmodified structures in an even, non-preferential manner. In turn, adhesion pattern of eukaryotic fungus Saccharomyces boulardii resembled that of fibro- and osteoblast cells rather than that of Staphylococcus. The discovered effect can be used for fabrication of personalized and smart implants in regenerative medicine. 
Keywords: PLLA, laser modification, hierarchical microstructure, casting extrusion, femtosecond laser, cellular response, personalized scaffolds

\section{INTRODUCTION}

Tissue engineering combines material sciences and cell biology to repair or replace damaged tissues with a synthetic scaffold [1-3]. The role of the scaffold is to provide mechanical support and physicochemical environment for cells proliferating on the scaffold surface $[1,4]$. For this reason, researchers try to design scaffold properties that would imitate natural environment of cells [4-6].

Synthetic polymers such as poly(L-lactide), poly(e-caprolactone) or poly(Llactide-co-glycolide) are nowadays widely investigated as potential materials for bioresorbable scaffolds. These polymers have some disadvantages such as high hydrophobicity and smoothness of the surface, which limit their applicability in regenerative medicine [7]. For this reason, many modifications of the bioresorbable polymers surfaces have been developed $[8,9]$. The most frequently used techniques include bulk modification (copolymers, polymer blends or composite systems) [10-13], chemical grafting [14,15], surface coating (with bioactive compounds or minerals) [1618], plasma modification [19-21] and, increasingly often, laser techniques [16,22-26].

In research on the cell-scaffold interactions, there are three main tissue engineering areas of interest, namely: 1) scaffold structure for tissue growth, 2) source of cells to facilitate the required tissue formation and 3) biophysical stimuli to direct the growth and differentiation of cells within the scaffolds [27]. Biophysical factors (topographical and mechanical properties of cell-adhesive materials) have been shown to regulate a variety of cellular functions such as migration, adhesion and proliferation [28-30]. For example, it was found that scaffold stiffness affects cell viability [31,32]. Stiffness of the biomaterial substrate is also one of the parameters that influence cell motility $[33,34]$. There are articles showing the possibilities of reprogramming cells in response to physical and topographical cues from the environment $[35,36]$. In turn, many other studies show that by appropriately designing the biophysical cues of biomaterials, it is possible to influence the differentiation of various types of stem cells towards specific cell lines, which play a significant role in a given biological process [37-39]. 
Recently, there has been an increased interest in laser techniques as a tool for modifying the surface of biomaterials based on biodegradable aliphatic polyesters. Thanks to the ability of controling numerous process parameters (radiation wavelength, average optical power or pulse energy, pulse duration, repetition frequency, scanning speed and the type of process gases), laser techniques allow one to precisely control the physicochemical phenomena occurring on the polymer surface. The use of laser radiation to modify the polymer surface creates the possibility of changing the surface chemistry (creating new polar functional groups) [16,40], surface topography (creating irregular or regular structures) [22,41-43], hydrophilicity [16,44] and degree of crystallinity of the substrate $[45,46]$. Because of their promising perspectives, lasers began to be used for precise surface modifications inducing a well-defined cellular response. The research by Izumi Takayama, in which he showed that structures consisting of laser-made craters significantly affect adhesion, proliferation and differentiation of cells from the myoblast lineage [47], can serve as an example. In another study, R. Ortiz showed that without biochemical factors influencing the surface topography, it is possible to force the differentiation of MSCs towards osteoblasts and control their orientation and development direction on the surface [25].

This paper presents a new type of a highly ordered structure with great potential for biomedical applications. For its production, a laser with an ultra-short pulse duration operating in the DLW (Direct Laser Writing) mode was used. The described structure consists of round-shaped protrusions evenly distributed on the surface, resembling shortbread cookies, which inspired the name of 'cookie structure'. Its high application potential has been confirmed by the research conducted on the fibroblast and osteoblast cell lines. The first of these lines is the principal active component of all kinds of connective tissues, while the another is primarily responsible for bone formation and recovery of bone fraction; therefore, both of them are crucial with regard to the potential applicability of 'cookie structures' in modern bone implants. Moreover, since the process of implantation is irreversibly related to the race to occupy the surface, a fight fought between patient's eukaryotic cells and the contaminating microorganisms (bacteria, fungi), the ability of S.aureus (pathogenic bacteria) to colonize the manufactured structures was also assessed. Following this path, we also scrutinized the ability of biotechnologically useful fungus referred to as Saccharomyces boulardii to colonize the modified and unmodified surfaces. 


\section{EXPERIMENTAL SECTION}

\subsection{Materials and preparation of samples}

In this research, we used poly (L-lactide) Resomer L210s (PLLA) supplied by Evonik, Germany. The investigations were carried out on PLLA in the form of foil approximately $200 \mu \mathrm{m}$ thick. The foils were extruded using a Labtech Engineering LE830/C (Sweden/Thailand) conical single screw extruder, equipped with a flat die combined with a micro cast film line LUMCR-75 at $200^{\circ} \mathrm{C}, 200 \mathrm{rpm}$. The foilwithdrawal speed was set at $0.5 \mathrm{~m} / \mathrm{min}$., based on the results of previous tests [45]. Before the extrusion process, the material in the form of granules was dried in a vacuum dryer at $60^{\circ} \mathrm{C}$ for 15 hours.

\subsection{Laser modification}

In the investigation we used a laser micromachining system of our own design, based on an ultrashort pulsed fibre laser, the TruMicro series 2020 from TRUMPF $\mathrm{GmbH}$. The laser source was operated at a fundamental wavelength of $1030 \mathrm{~nm}$ with a maximum output power of $20 \mathrm{~W}$ and a beam quality factor of $M^{2}<1.15$. The pulse repetition rate $(P R R)$ was fixed at $10 \mathrm{kHz}$. In the experiment we used constant pulse duration of $260 \mathrm{fs}$ selected in preliminary tests from the available range from $260 \mathrm{fs}$ to 20 ps. The system was equipped with a galvanometric optical scanning system, IntelliSCAN ${ }_{\mathrm{se}} 14$ from SCANLAB GmbH, that allows the beam to be deflected within the sample area. Next, the laser beam was focused on the target through a $163 \mathrm{~mm}$ focal length F-Theta lens type S4LFT1163 from Sill Optics GmbH. The beam diameter at the focal point was approximately $2 \omega_{0}=45 \mu \mathrm{m}$. Taking into account the equivalent Top Hat radius for a cylindrical Gaussian beam $d=\sqrt{2} \omega_{0}$, the fluence was defined as $F=$ $2 E_{p} / \pi \omega_{0}^{2}$ for a single point. The pulse energy was measured at the end of the optical path - above the sample surface. A summary of process parameters for the modified surface is given in Table 1. After surface structuring, the samples were cut out from the polymer sheet using the following parameters: pulse energy $82 \mu \mathrm{J}\left(F=10.3 \mathrm{~J} / \mathrm{cm}^{2}\right)$, cutting speed $100 \mathrm{~mm} / \mathrm{s}$, pulse repetition rate $50 \mathrm{kHz}$ and 15 repetitions of the process. A block diagram of the system is shown in Fig. 1. 
Tab. 1. Laser modification parameters

\begin{tabular}{lcccc}
\hline $\begin{array}{c}\text { Method of } \\
\text { sample } \\
\text { modification }\end{array}$ & $\begin{array}{c}\text { Pulse energy } \\
E_{p}\end{array}$ & $\begin{array}{c}\text { Fluence } \\
{[\mu \mathrm{J}]}\end{array}$ & $\begin{array}{c}\text { Scanning } \\
\text { speed } \\
V\end{array}$ & $\begin{array}{c}\text { Line spacing } \\
d_{x}=d_{y}\end{array}$ \\
\cline { 3 - 5 } $\begin{array}{c}\text { - a grid of } \\
\text { points }\end{array}$ & 54.5 & 6.85 & 500 & $\left.5 \mu \mathrm{J} / \mathrm{cm}^{2}\right]$ \\
\hline
\end{tabular}

a)

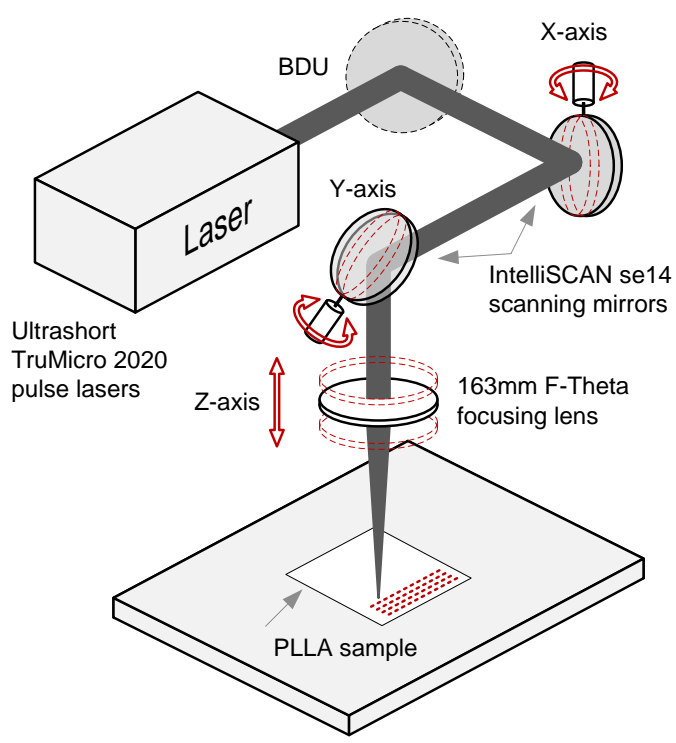

b)

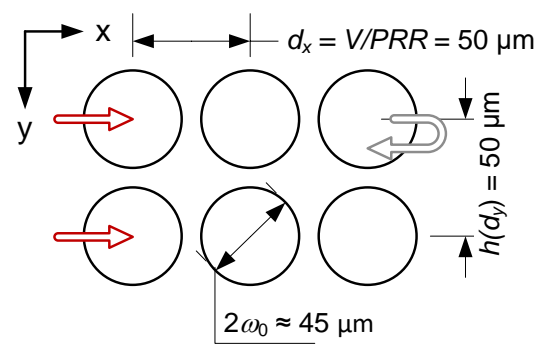

Fig. 1. Sample preparation: a) block diagram of the laser system used in the experiment, where BDU schematically represents Beam Delivery Unit, b) scanning procedure where $d_{x}$ and $d_{y}$ are the pulse spacing, $2 \omega_{0}$ is the laser spot diameter, $V$ is the scanning speed and $P R R$ is the pulse repetition rate of the laser

\subsection{Optical profilometry}

In order to accurately analyze the surface topography of the tested samples, a confocal Olympus Lext 5000 microscope, equipped with a diode laser generating radiation with a wavelength of $405 \mathrm{~nm}$ was used. A 100x lens was used for observation.

\subsection{Scanning Electron Microscopy (SEM)}

The surface morphology of modified foils was observed using SEM. For this purpose, a Zeiss Sigma 500 VP Scanning Electron Microscope in the BSE (Backscattered-Electron Imaging) detector mode was used. The microscope operated at $20 \mathrm{kV}$, with the magnification range from $100 \mathrm{x}$ to $2000 \mathrm{x}$, in a vacuum below $10^{-5}$ mbar. Samples were covered with $\mathrm{Au}$ (sputter current: $40 \mathrm{~mA}$, sputter time: $50 \mathrm{~s}$ ) using a QUORUM machine and dried at the critical point in a Leica EM CPD300 dryer before the measurements.

In order to visualize the cross-section of the sample, a brittle fracture of the modified foil was made after freezing with liquid nitrogen. 
The SEM analysis was performed to visualize cell colonies (osteoblasts and fibroblasts) on the modified surfaces. The microscopy procedure was carried out as follows: First, the samples with osteoblasts and fibroblasts were fixed for $15 \mathrm{~min}$ at room temperature using a $3 \%$ glutarate $(\mathrm{POCH}$, Gliwice, Poland). Next, the samples were rinsed twice with a phosphate buffer (Sigma-Aldrich) to eliminate the fixative. After that, they were dehydrated in increasing concentrations of ethanol $(25,60,95$, $100 \%$ ) for $5 \mathrm{~min}$ in each solution. Finally, from that point onward, the samples were prepared as per the procedure for the surface without biological material (described above).

\subsection{Water contact angle measurement}

The water surface tension measurements were conducted with a PG-X contact angle goniometer (Testing Machines, Inc.). At least 10 measurements for each sample were performed and the mean value as well as the standard deviation were calculated for these results.

\subsection{Spectroscopic chemical analysis (ATR/FTIR)}

For infrared spectroscopy analysis a FTIR Nicolet TM 8700 spectrometer with the Smart Orbit Diamond ATR accessory (Thermo Fisher Scientific Inc.) was used. The measurement was made in the range of $600-4000 \mathrm{~cm}^{-1}$ wavenumbers with a $0.48 \mathrm{~cm}^{-1}$ step.

\subsection{Gel Permeation Chromatography (GPC)}

Gel permeation chromatography (GPC) analysis was performed in $\mathrm{CHCl}_{3}$ at $35^{\circ} \mathrm{C}$ with an eluent flow rate of $1 \mathrm{~mL} / \mathrm{min}$. For the process, a VISCOTEK VE1122 pump was used in a set with two high-performance PLgel $5 \mu \mathrm{m}$ Mixed-C columns. The system was equipped with an RI detector (Shodex SE 61) allowing the determination of the polymer polydispersity index (PDI) and the determination of number (Mn) and weight $(\mathrm{Mw})$ average molecular weights based on a conventional calibration curve made for narrow polystyrene standards. The obtained solutions with a concentration of less than $0.3 \%$ were filtered through a filter with a pore diameter of 0.46 micrometers.

\subsection{Evaluation of samples' cytotoxicity toward fibroblast and osteoblast cell lines}

Neutral Red (NR) cytotoxicity assay was performed toward osteoblast (U2-OS, ATCC, Manassas, VA, USA) and fibroblast (L929 ATCC, Manassas, VA, USA ) cell 
cultures treated with an extract obtained from the reference and the modified samples conditioned medium. The extracts were prepared according to ISO 10993: Biological evaluation of medical devices; Part 5: Tests for in vitro cytotoxicity; Part 12: Biological evaluation of medical devices, sample preparation and reference materials (ISO 109935:2009 and ISO/IEC 17025:2005). After 24 hours of incubation of cells, the conditioned medium was removed and $100 \mu \mathrm{L}$ of the NR solution (40 $\mu \mathrm{g} / \mathrm{mL}$; SigmaAldrich, Germany) was introduced into the wells of the plate. Cells were incubated with $\mathrm{NR}$ for $2 \mathrm{~h}$ at $37^{\circ} \mathrm{C}$. After incubation, the dye was removed, wells were rinsed with phosphate buffer saline (PBS, Sigma Aldrich, Germany) and left to dry at room temperature. Subsequently, $150 \mu \mathrm{L}$ of a de-stain solution $(50 \%$ ethanol $96 \%$, $49 \%$ deionized water, $1 \%$ glacial acetic acid; $\mathrm{POCH}$, Poland) was introduced to each well. The plate was vigorously shaken in a microtiter-plate shaker (MTS4, IKALabortechnik, Germany) for 30 min until NR was extracted from the cells and formed a homogenous solution. Next, the value of NR absorbance was measured spectrometrically using a microplate reader (Multi-scan GO, Thermo Fisher Scientific, Waltham, MA, USA) at $540 \mathrm{~nm}$. The absorbance value of cells not treated with extracts was considered $100 \%$ of the potential cellular growth (positive control). All the analyses were performed in 6 repeats.

\subsection{Evaluation of fibro- and osteoblasts' colonization on analyzed samples}

$1,5 \mathrm{ml}$ of the cell suspension with a density of $1,5 \times 10^{5} / \mathrm{mL}$ was seeded to the well in a 24-well plate (VWR, Randor, Pa, USA) with an insert at the bottom. Plates were incubated for $24 \mathrm{~h}, 48 \mathrm{~h}$ and $72 \mathrm{~h}$ at $37^{\circ} \mathrm{C}$ and $5 \% \mathrm{CO} 2$ (C150UL-CO2 incubator, Binder, Tuttlingen Germany). The medium was exchanged every day. Next, the Neutral Red uptake technique was performed using the protocol described in subsection 2.7. All the analyses were performed in 6 repeats.

\subsection{Assessment of the differences between density of fibroblast cells colonizing the unmodified or modified surface of the laser-modified sample}

The fibroblasts of $1,5 \mathrm{ml}$ of cell suspension with a density of $1.5 \times 10^{5} / \mathrm{mL}$ were seeded to the well in a 24-well plate (VWR, Randor, Pa, USA) with the sample at the bottom. Plates were incubated for $24 \mathrm{~h}, 48 \mathrm{~h}$ and $72 \mathrm{~h}$ at $37^{\circ} \mathrm{C}$ and $5 \% \mathrm{CO} 2$ (C150UL$\mathrm{CO} 2$ incubator, Binder, Tuttlingen Germany). The medium was exchanged every day. Next, the medium was removed and replaced with $2 \mathrm{~mL}$ of PBS buffer containing $3 \mu \mathrm{L}$ 
of SYTO 9 green fluorescent nucleic acid stain (Thermo Fisher Scientific, Waltham, MA, USA) dyeing cells green. The setting was incubated for $15 \mathrm{~min}$ at room temperature and protected from light. Next, the buffer was removed and the inserts were gently rinsed 3 times using the PBS buffer without dye. After rinsing, the modified samples were turned upside down and placed in a fresh 24-well plate in such a manner that the cell-containing surface adhered to the well surface. Pictures of the dyed cells were then taken using a Lumascope 620 (Etaluma, Carlsband, CA, USA) with a 20x magnification. The captured fields of vision contained both unmodified and modified surfaces. Next, the pictures were processed using ImageJ (National Institutes of Health, Bethesda, MD, USA). The pictures' forming channels were split and the green channels were subjected to further analyses. The two Regions of Interests (ROI) of exactly the same size were established in each picture in such a manner that one ROI covered the unmodified, while the other covered the modified part of sample's surface. Lastly, the mean grey value (MGV) of each ROI was measured. The values of MGV correlate positively with the intensity of green. In turn, the intensity of green correlates positively with the number of eukaryotic cells within the field of vision. Six random fields of vision (and 12 ROIs) from three samples were taken for this analysis.

\subsection{Potential application of the modified sample's modification to control the adhesion of cells as exemplified by fibroblasts}

This analysis was performed analogically to the colonization assay described in subsection 2.8. The procedure of fibroblasts' dyeing using the SYTO-9 green fluorescent nucleic acid stain was performed analogically to the method described in subsection 2.9. The visualization of dyed cells was performed using a Lumascope 620 (Etaluma, Carlsband, CA, USA) with a four-fold magnification. For the samples with letters $\mathrm{H}, \mathrm{A}, \mathrm{N}, \mathrm{N}, \mathrm{A}$, this analysis was performed three times, each time with a different incubation (24h, 48h and $72 \mathrm{~h}$ ). The procedure for the 'lightening' sign was analogous. The field of vision obtained after the four-fold magnification allowed us to cover one letter at a time. Thus, the entire word 'HANNA' made of fibroblasts (Fig. 9), actually consists of 5 separate pictures, while the 'lightening' sign is actually composed of 6 separate pictures. 


\subsection{Ability of the nosocomial Staphylococcus aureus and the biotechnologically- important Saccharomyces boulardii to colonize the analyzed samples}

The strains applied in this analysis were S.aureus ATCC 6538 (Manassas, VA, USA) and the probiotic S. boulardii strain SB77 from the collection of the Pharmaceutical Microbiology and Parasitology Department at Wroclaw Medical University. The loop of the staphylococcal or yeast culture grown on the Columbia or Sabouraud agar plate, respectively (BioMaxima, Poland) was transferred to liquid Tryptone Soya Broth (TSB, BTL, Poland) and incubated at $37^{\circ} \mathrm{C}$ for $24 \mathrm{~h}$. Next, the culture's optical density of 1 McFarland was established using a densitometer (DensiLa-Meter II, Erba, Czech Republic) (Biomerieux, Poland). After that, the suspension was diluted in the Miller-Hinton Broth (M-H, BioMaxima, Poland) to reach the density of $1 \times 10^{5}$ cells $/ \mathrm{mL}$. Next, $1 \mathrm{~mL}$ of the microbial suspension was introduced to the well of a 24-well plate containing modified samples and was incubated for another $24 \mathrm{~h}$. After incubation, the samples were transferred to $1 \mathrm{ml}$ of a $0.1 \%$ saponine and were subjected to vigorous vortex-mixing using a Multi-Vortex V-32 (Biosan, Poland). After mixing, the obtained cell-containing suspension was serially diluted and cultured on appropriate agar plates (Columbia Agar for Staphylococcus, Sabouraud Agar for Saccharomyces) and incubated at $37^{\circ} \mathrm{C}$ for $24 \mathrm{~h}$. After incubation, the number of colony forming units was calculated. All the analysis were performed in triplicates.

\section{RESULTS AND DISCUSSION}

\subsection{Surface characterization}

The scanning electron microscopy technique allowed for the initial visualization of the structure produced on the PLLA surface. The obtained results are shown in figure 2. First, the focus was on the surface of the base material - the unmodified PLLA film (A). The material forming technique used (extrusion combined with casting) allows one to obtain a film with a smooth surface, and a small number of defects. Consequently, the modification could be carried out homogeneously by uniformly focusing the laser beam over the entire surface. 

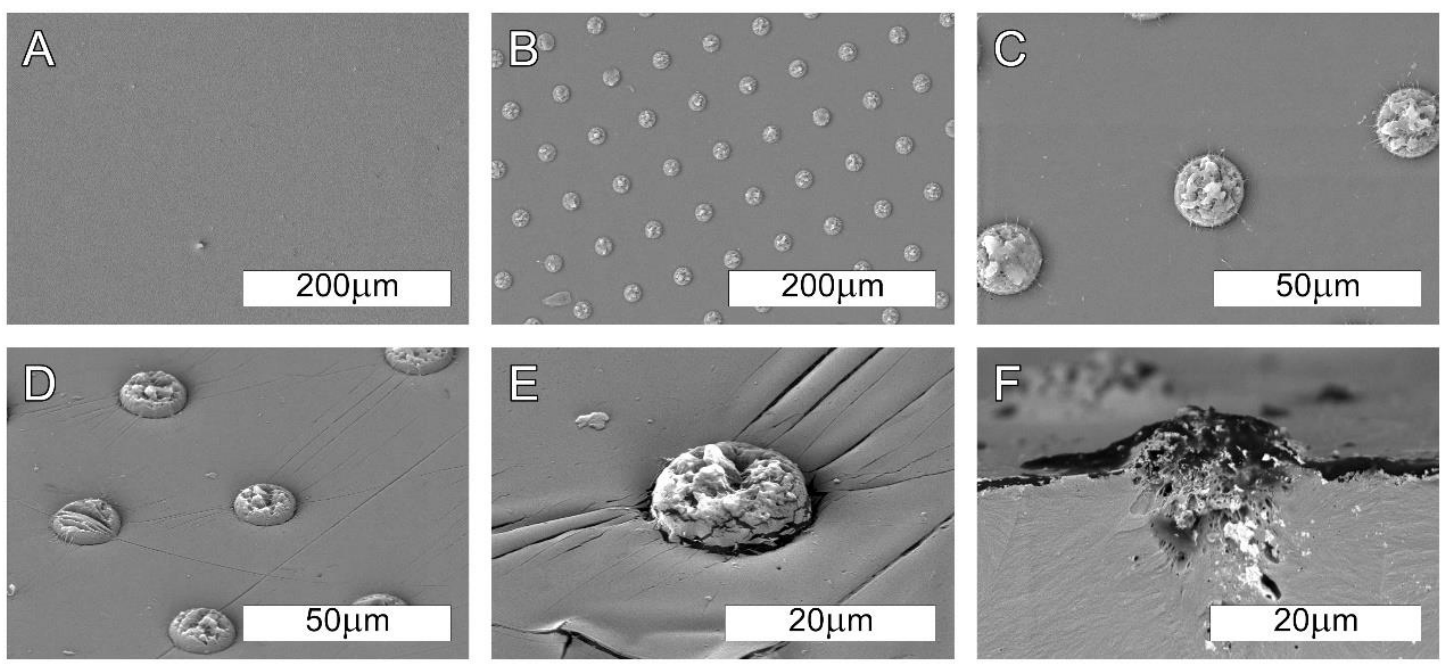

Figure 2. Pictures showing the 'cookie structure' obtained on the surface of a polylactide film:

A) unmodified PLLA surface; B), C) top view; D), E) at an angle of about $45^{\circ}$; F) Cross section of a single 'cookie'.

Figure 2B shows a modified PLLA surface. The surface was irradiated with single pulses of a femtosecond fiber laser according to the procedure described in subsection 2.2. The modified areas (circular forms in top view) distinctly stand out against the background of the sample and display a clear long-range order. The distances between them result directly from the sample's exposure parameters in both $\mathrm{X}$ and $\mathrm{Y}$ axes (scanning speed combined with PRR and line spacing). Image $\mathrm{C}$ shows a clear difference in the morphology of the modified regions compared to the unmodified ones. For a more detailed analysis of the shape and vertical orientation of the modified areas, SEM pictures were taken at an angle of $45^{\circ}$ to the sample's surface. The obtained images are shown in Figure $2(\mathrm{D}, \mathrm{E})$. As can be seen, the modified areas are in the shape of rough protrusions, similar in structure to 'shortbread cookies'. Despite their highly orderly pattern and the constant parameters of laser pulses, individual 'cookies' vary slightly in shape and roughness, remaining round-shaped in the top view. In order to better understand the formation mechanism of these protrusions in the laser-modified material, it was decided to investigate the polymer structure below such 'cookies'. For this purpose, brittle cross sections of several modified samples were made (frozen with liquid nitrogen) and a crack coinciding with a single 'cookie' was searched for. Then it was visualized (figure $2 \mathrm{~F}$ ). The figure shows a clear loss of material to a depth of about 15 micrometers below the base line of the sample, manifested by the formation of a porous structure. 
Swelling of material due to single pulses of a femtosecond sapphire laser operating at a wavelength of $800 \mathrm{~nm}$ has been observed earlier by Guangchao Ye. However, in this case the bulge of the polymer was shapeless and reached a diameter several times larger than that obtained in our experiment [48]. A similar effect formation of regularly shaped protrusions - was obtained by B. Stepak during irradiation of the PLLA surface with a femtosecond fiber laser at a wavelength of 515 nm [46]; however, the phenomenon was not investigated any further.

According to literature reports, laser swelling of polymer is the initial stage of ablation of the material for the case where pulse energy is still too low to cause a noticeable loss of the surface layer of the material $[46,48,49]$. Ultra-short, high-energy laser pulses generate stresses in the top layer of the material, causing swelling on the surface, while simultaneously initiating the expansion of voids in the subsurface area. Additionally, if the thermal effect associated with radiation is large enough, the material melts locally and degrades partially with the release of volatile chemicals. Their accumulation under the surface of the material combined with the hot air bound in the polymer structure (higher temperature - increased air volume) contributes to an increase in pressure and ejection of the molten polymer to the surface as a result of a local 'eruption'. Under the influence of ambient temperature, the material cools down, creating a protrusion on the surface. As a consequence of this process, the material beneath the base surface of the protrusion becomes porous.

Farhana Baset et al. simulated a similar process by using Molecular Dynamics approach on the example of PMMA [49].

Figure 3 summarizes surface profiles, linear profiles and water contact angles of the modified and unmodified PLLA films. As shown, surface topography studies with the use of an optical profilometer are complementary to the results of SEM analysis. Referring to Figure 3A, a high smoothness of the unmodified surface can be seen. The average roughness $\left(R_{a}\right)$ determined from the surface profile is only $49 \mathrm{~nm}$. The contact angle (set for distilled water) is characteristic of PLLA, which exhibits its hydrophobic properties and is approx. $78.8^{\circ}$. The situation is different with the modified PLLA film (Figure 3B). On the surface, regularly distributed protrusions, created under the influence of laser, are visible. The average roughness parameter $R_{a}$ determined for the modified surface is $289 \mathrm{~nm}$, which is almost one order of magnitude different from that of the reference surface. However, it is not a quantity that accurately illustrates the surface condition, because the higher value of roughness occurs only locally. Therefore, 
the value of the average roughness within the protrusions was determined, which is approx. $560 \mathrm{~nm}$. In contrast, the roughness for the areas around the 'cookies' is practically identical to that of the reference sample. The dimensions of individual protrusions are shown in the linear profile. As can be seen, they have a diameter of about $20 \mu \mathrm{m}$ at the base, while their highest points protrude above the surface by $3 \mu \mathrm{m}$. The irregularities formed on the surface also affect its wettability in the macroscale. A slight decrease in the contact angle (by about $6.6^{\circ}$ ) is observed.

\section{A) Unmodified surface}

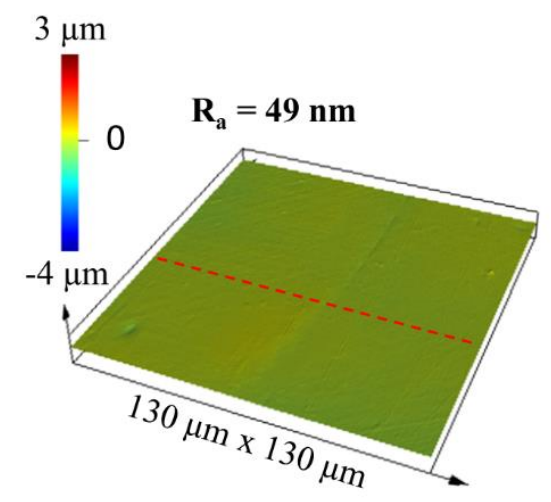

B) 'Cookies structure'
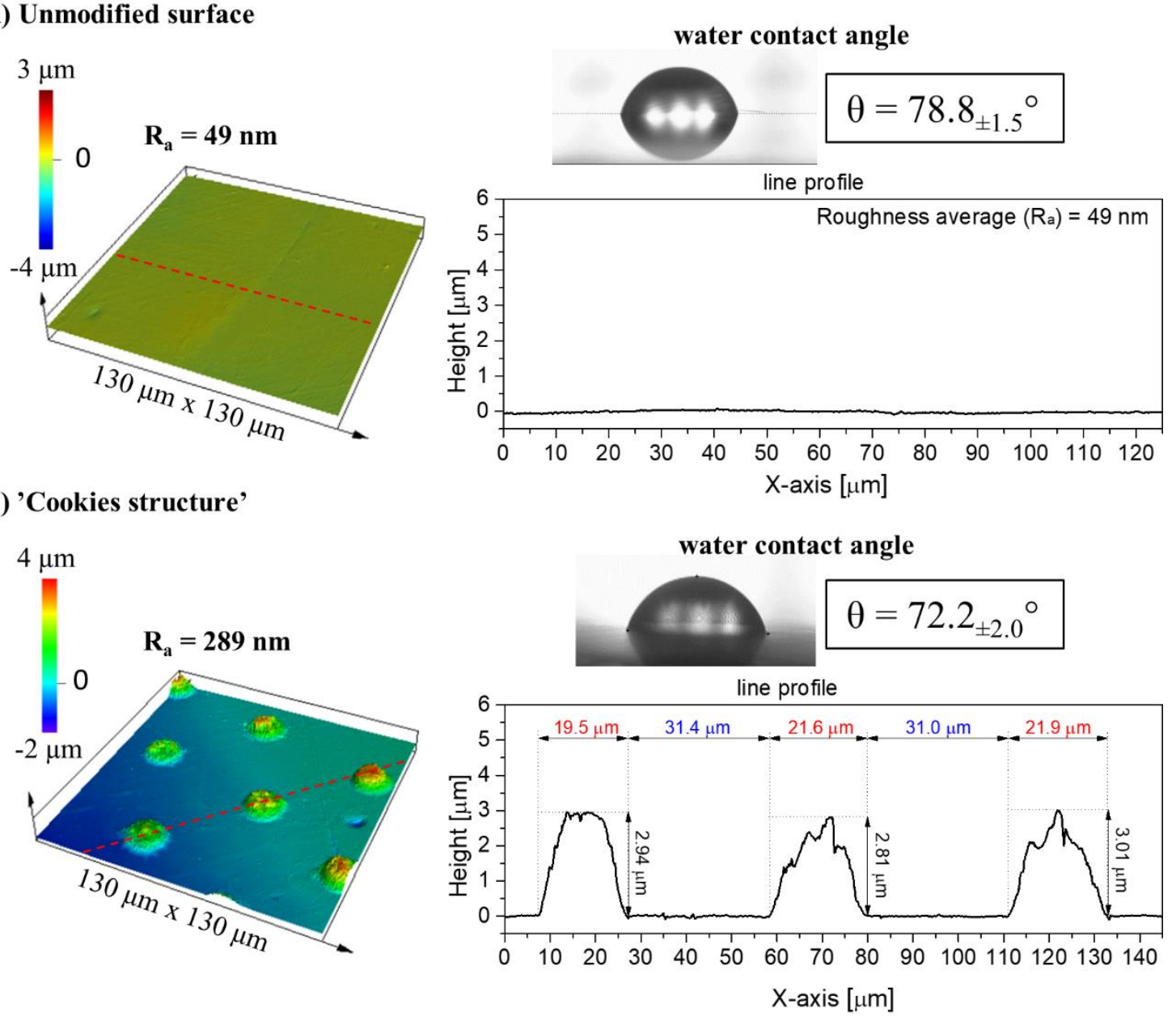

Figure 3. Characteristics of surface topography, taking into account the surface profile (Ra - roughness average value), linear profile and water contact angle for A) reference surface, B) 'cookie' structure. The red lines on the $3 \mathrm{D}$ profiles show where the linear profiles were recorded.

\subsection{Chemical changes, polymer degradation}

In order to determine the effect of laser radiation on the chemical structure of PLLA, FTIR/ATR spectroscopy measurements were performed. The obtained results are shown in Fig. 4. The curve for the reference sample is marked in black, while for the 
modified sample - in red. The course of the reference curve is consistent with the literature data for pure PLLA [50,51]. When analyzing the graph, only subtle changes are visible for the PLLA sample after laser modification. In the first place, a decrease in the intensity of the basic absorption bands can be noticed, which is a phenomenon usually associated with laser modification. The lowering of the intensity occurs mainly for the bands associated with the vibrations in the ester group $\left(\mathrm{v}(\mathrm{C}=\mathrm{O}) \sim 1747 \mathrm{~cm}^{-1}\right.$, $\left.\mathrm{V}_{\mathrm{as}}(\mathrm{COC}) \sim 1180 \mathrm{~cm}^{-1}, \mathrm{v}_{\mathrm{s}}(\mathrm{COC}) \sim 1081 \mathrm{~cm}^{-1}\right)$, indicating the partial breakdown of these groups due to polymer degradation [50]. In addition, the appearance of new small bands is observed, which indicate the changes in the chemical structure of the PLLA. The first of these bands appears in the spectral range $1600-1700 \mathrm{~cm}^{-1}$ and is responsible for valence vibrations $\mathrm{v}\left(\mathrm{C}=\mathrm{C}\right.$ ). The second one (with a maximum at $\sim 811 \mathrm{~cm}^{-1}$ ) is responsible for the deforming vibrations of the $\delta \mathrm{CH}$ and $\delta \mathrm{CH} 2$ in other degradation products - ketones $(\mathrm{RCOCH}=\mathrm{CH} 2)$ or vinyl ethers $\left(\mathrm{ROCH}=\mathrm{CH}_{2}\right)[50]$. However, it should be emphasized that the observed changes are small, indicating a slight interference in the chemical structure of the polymer. Moreover, the performed spectroscopic analysis does not show the occurence of any other functional groups on the surface.

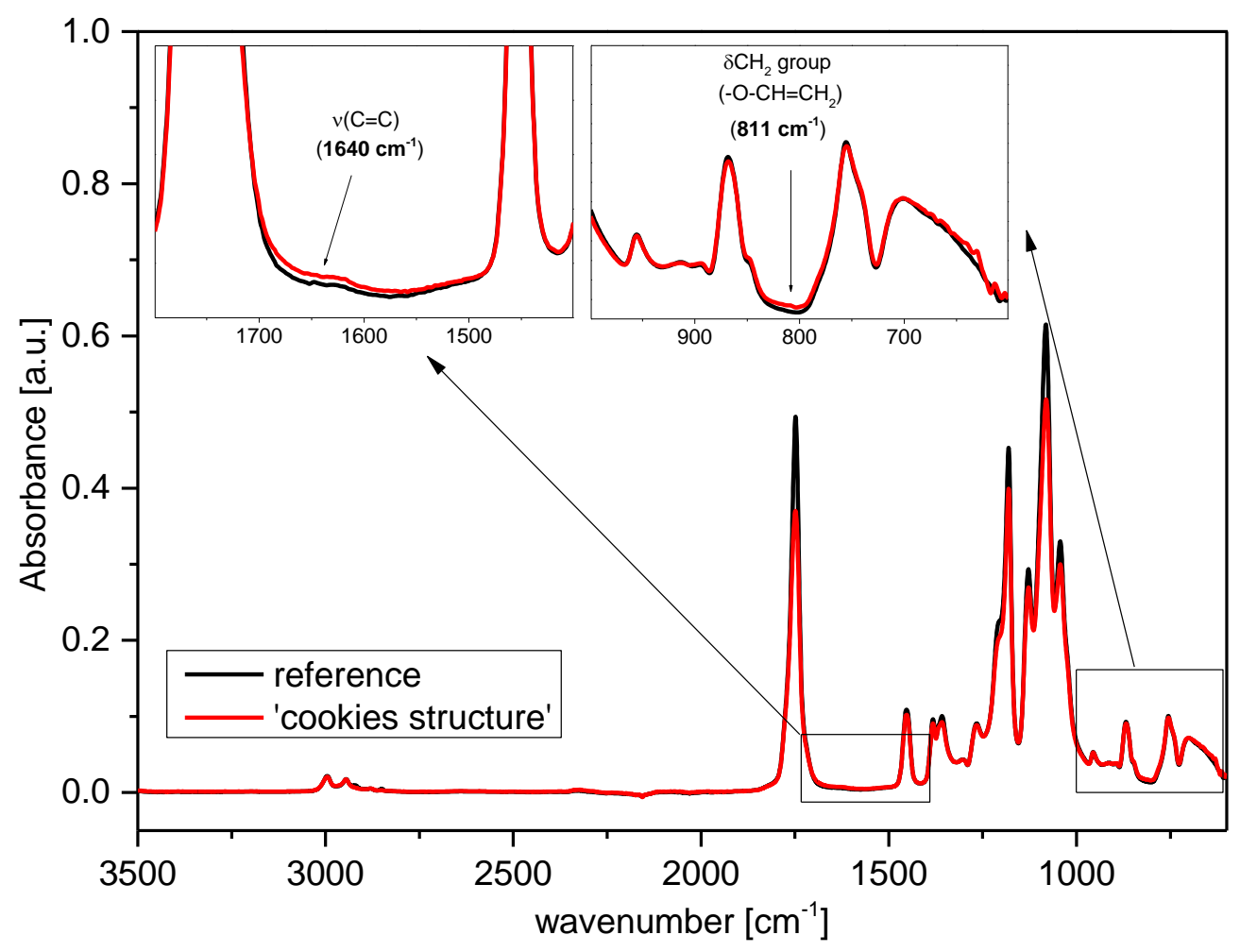

Figure 4. FTIR/ATR spectra of laser-modified and unmodified areas 
To quantify PLLA degradation during laser modification, GPC measurements were performed. Figure 5 shows the molecular weight distribution curves for both samples. Only a slight decrease in molecular weight can be noted for the structured sample. The number average molecular weight parameter decreased by less than $5 \%$. The same applies to the polydispersity index. This shows that the modification carried out to a limited extent degrades the material, without causing significant chemical changes in its volume. This is in line with the results of the FTIR spectroscopic analysis.

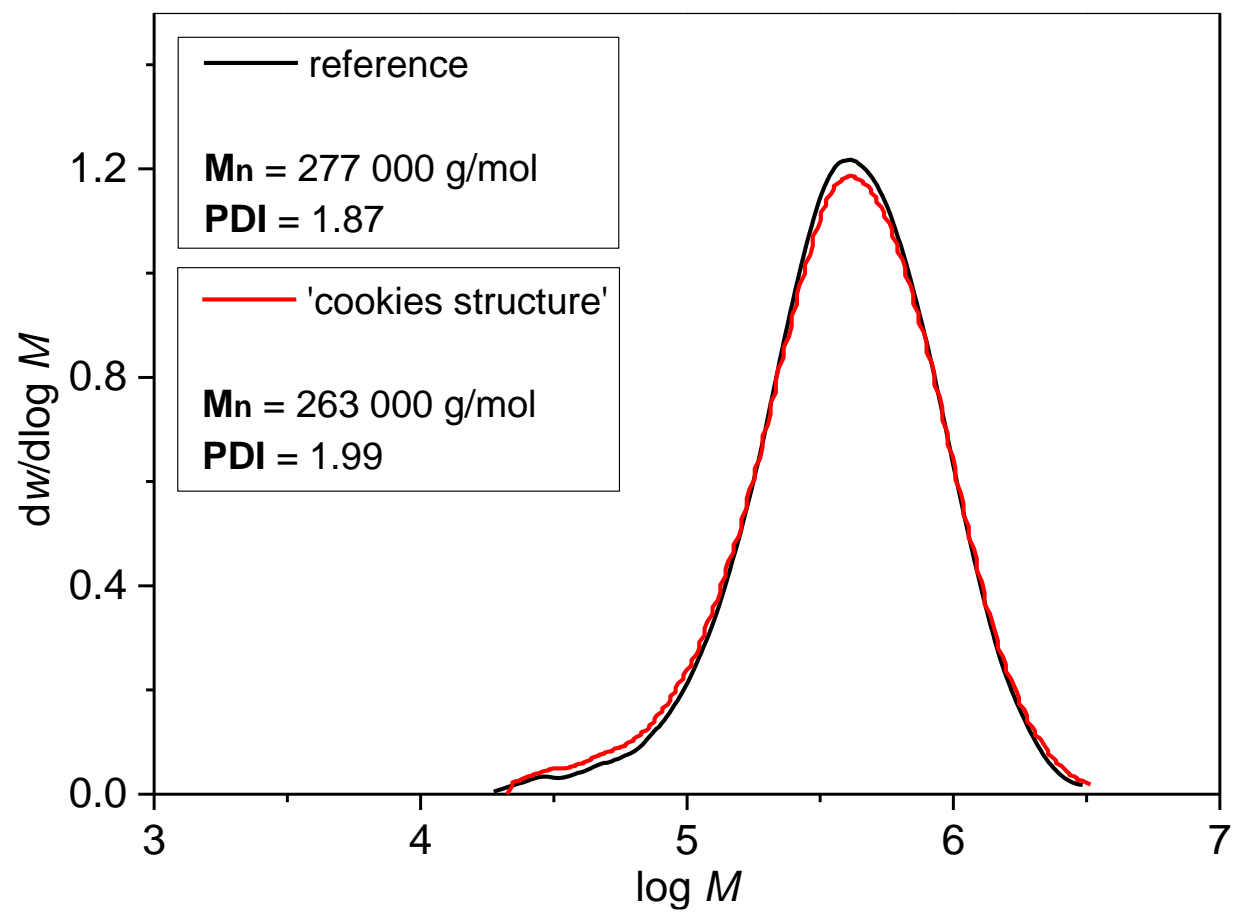

Figure 5. Molecular weight distribution curves for unmodified (reference) and modified ('cookies structure') samples. $\mathrm{M}_{\mathrm{n}}$ - number average molecular weight, PDI - polydispersity index.

The use of laser radiation for polymer modification is inextricably connected with the degradation of polymer chains. Therefore, laser processes are often associated with the formation of large amounts of low molecular weight compounds that may have a toxic effect on cells [52]. The advantage of the proposed surface modification method is the maximum reduction of polymer degradation for the following reasons: 1) the surface is irradiated with single pulses - most of the surface remains intact, 2) the energy of a single laser pulse is only slightly above the polymer ablation threshold, causing only slight changes in a small volume of the material. 


\subsection{Biological response}
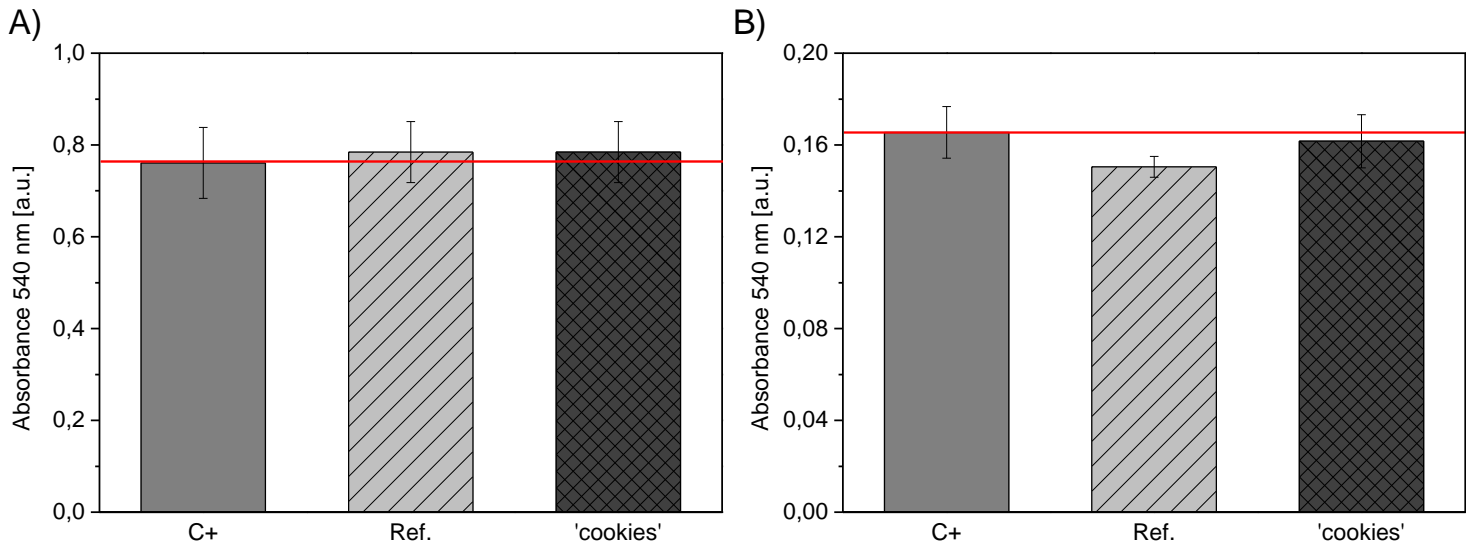

Figure 6. Viability of A) fibroblasts and B) osteoblasts exposed to extracts from samples for 24h. C+: viability of untreated cells (positive control of growth). Red line indicates the level of viability considered $100 \%$.

A)

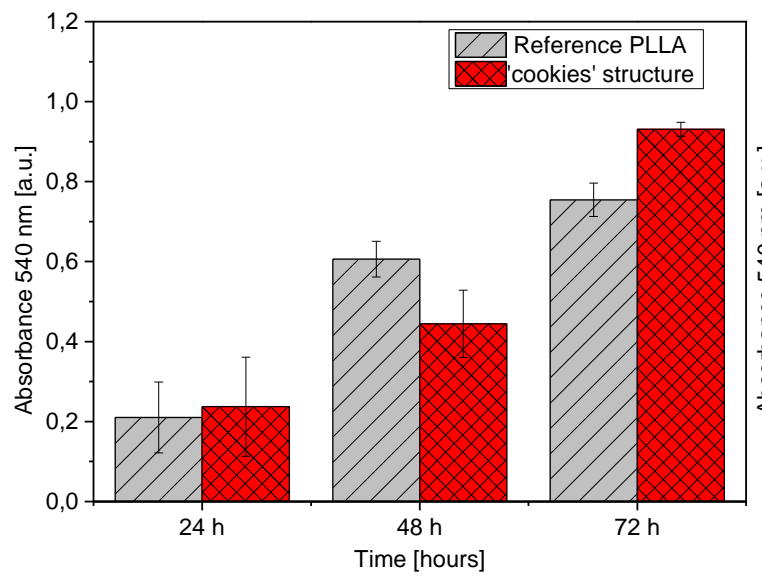

B)

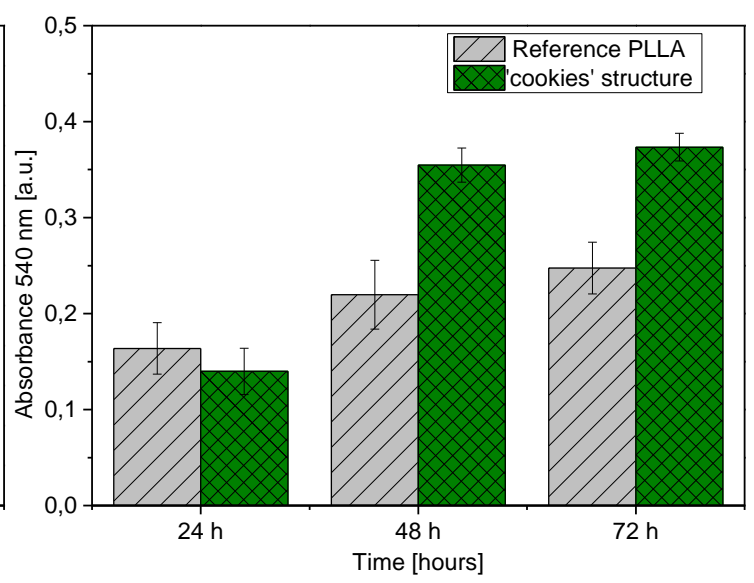

Figure 7. Colonization of analyzed samples within 24-72h period. A) fibroblast; B) osteoblast cell line.

The results of a normative test of cytotoxicity of analyzed biomaterials are presented in Figure 6. The calculated average percentage of fibroblast viability exposed to medium incubated with the reference and structured samples, was 103 and $96 \%$, respectively. The analogous parameters measured for osteoblasts were: 90 and $97 \%$. The standard deviation of means did not exceed $10 \%$. We have observed no significant changes in the fibroblast and osteoblast morphology. The cytotoxicity of analyzed samples did not exceed $30 \%$ in cell viability (Figure 6), and the changes in morphology were at grade $0 / 1$ with regard to normative description. Thus, all analyzed samples are non-cytotoxic for both fibro- and osteoblast cell lines.

In the next line of investigation, we have performed an analysis of the pace of fibro- and osteoblast colonization on the analyzed surfaces (Figure 7). The differences 
in this parameter, measured by the number of cells adhered to the samples within specific time points (24h-48h-72h) exhibited surface- and cell line-dependent interplays. The general trend was that fibro- and osteoblasts increased their number in subsequent days of culturing, independently of type of surface they adhered to. One interesting pattern was observed with regard to the cell growth. A high growth of cells between 24 and $48 \mathrm{~h}$ of incubation and, subsequently, a slow growth between 48 and $72 \mathrm{~h}$ could be observed (this pattern is exemplified by osteoblasts developed on the modified surface).

\section{A) fibroblasts}
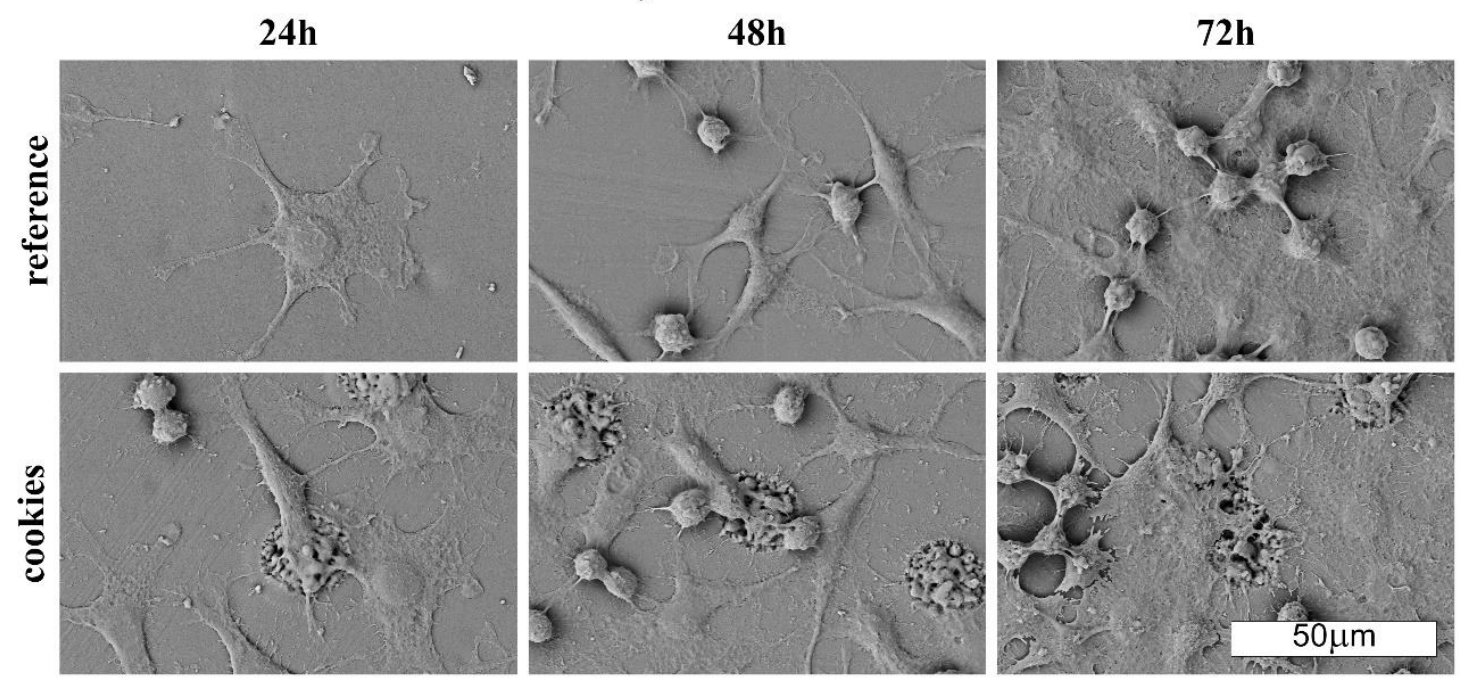

\section{B) osteoblasts}

$24 h$
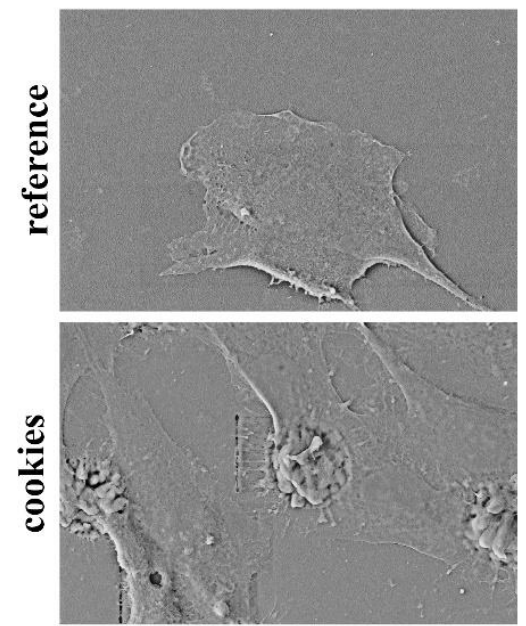

$48 h$
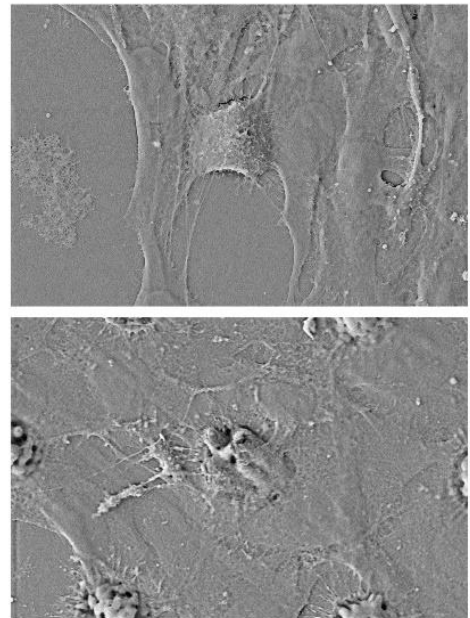

$72 \mathrm{~h}$

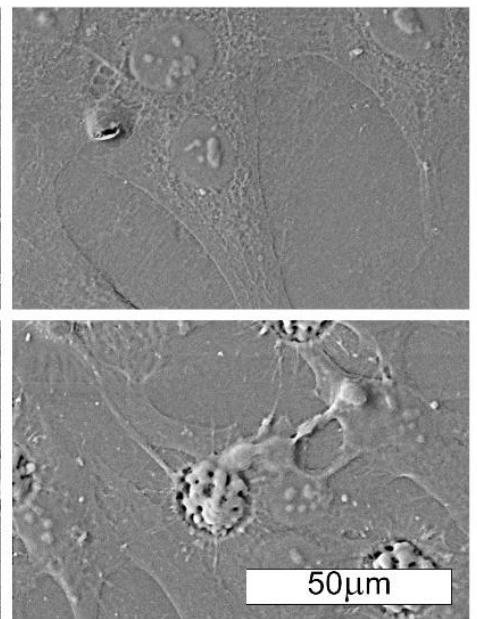

Figure 8. Morphology of cells colonized on analyzed samples within 24-72h. A) fibroblast; B) osteoblast cell line. Presented images show elongated, firmly adhered cell lines of proper morphology. Please note the cellular protrusions (part A, lower panel) hooked into the cookie structures. 
Since bioresorbable polylactides are considered to be one of the most important materials for tissue engineering applications, there is a vast evidence showing their low cytotoxicity, and the possibility of eukaryotic cells to spread and multiply on them [5355]. Results presented in Figure 6, Figure 7 and Figure 8 are not only in line with these reports (showing no cytotoxicity of PLLA towards fibro- and osteo-blasts), but also indicate that the performed laser modification did not negatively alter these aforementioned favorable properties of the PLLA surfaces.

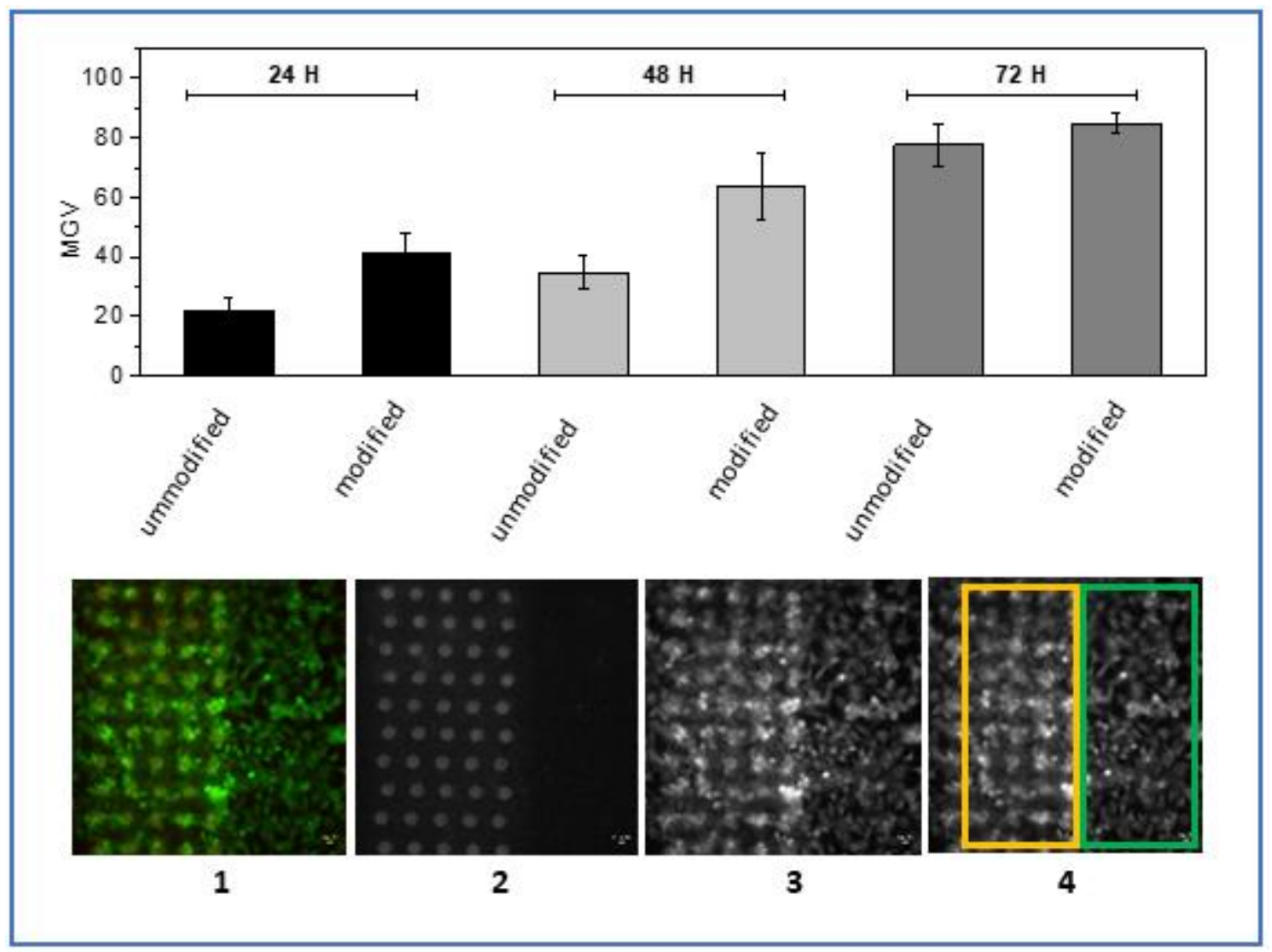

Figure 9. Differences between the density of fibroblast cells colonizing unmodified or modified surface within the same modified sample within 24-72h of incubation. MGV- mean grey value; 1) fibroblast colonizing sample, visualized with green dye; 2) picture sample containing modified (dot-covered) and unmodified (black) areas; 3 ) picture 1 is split to obtain grey pixels reflecting intensity of green color; 4) regions of interests (ROI) of exactly the same size covering modified (orange ROI) and unmodified (green ROI) areas.

Moreover, we have observed that the modified surfaces were colonized by a statistically higher number of cells (Figure 9) than the unmodified ones (K-W test, $\mathrm{p}<0.05)$. Following this observation we have performed an analysis utilizing fluorescence microscopy (Figure 10) to study this phenomenon. It turns out that fibroblast cells strongly adhered to the modified sample surface during the first $24 \mathrm{~h}$ of incubation (Figure 10 - 24h) and started to spread over unmodified surfaces during the 
next 24 hours (Figure $10-48 \mathrm{~h}$ ). After 72 hours of incubation the cells were spread evenly throughout the entire surface of the sample (Figure $10-72 \mathrm{~h}$ ); however, the density of cells was still higher within the modified areas. Thus, we hypothesized that the sample modification might be applied for directed colonization of eukaryotic cells and to test this hypothesis we performed various experiments with spatial patterns (such as the lightening sign shown in Figure 10C) and settled them with cells.

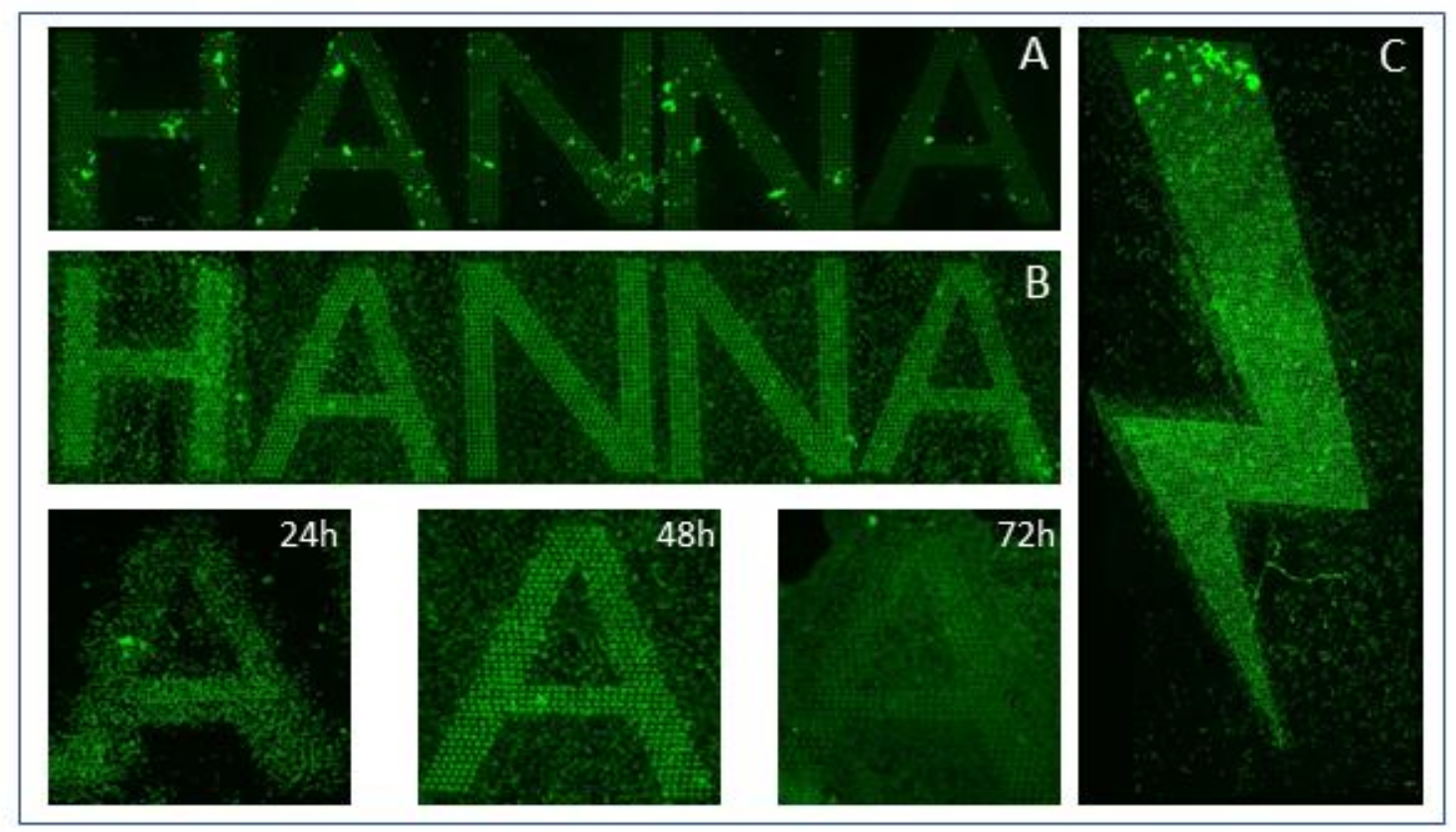

Figure 10. Potential application of presented laser modification method to control cell adhesion. The word 'Hanna' made of fibroblasts after A) 24h; B) $48 \mathrm{~h}$ hours of incubation; C) the lightening sign made of fibroblasts after $48 \mathrm{~h}$ of incubation. Pictures signed $24,48,72 \mathrm{~h}$ show preferential settlement of fibroblasts within the area of modified surface [24h] and gradual development of cells into unmodified areas after 48 and 72h. Pictures A and B are composed of 5 individual pictures; picture $\mathrm{C}$ is composed of 6 individual pictures. Individual pictures are presented in Supplementary Information (Figure S1). LumaScope 600, magn.x4.

Finally, bearing in mind the potential biomedical application of obtained surfaces, we scrutinized the ability of a nosocomial pathogen, Staphylococcus aureus, to adhere to the reference and modified samples. Results of parametric analysis (quantitative culturing) are shown in Figure 11A. Staphylococcus aureus was able to adhere to all types of analyzed samples evenly and non-preferentially. Following this lead, we analyzed ability to adhering to the samples of a biotechnologically-important fungus, referred to as Saccharomyces boulardii. This microbe was also able to adhere to and thrive on the surfaces of all types of analyzed samples, but it adhered more eagerly to the modified surfaces (Figure $11 \mathrm{~B}$ ). Interestingly, S. boulardii is an eukaryotic, oval cell, approximately $10 \mu \mathrm{m}$ long by $5 \mu \mathrm{m}$ wide [56]; Staphylococcus, in turn, is a significantly smaller bacterium (approximately $1 \mu \mathrm{m}$ in diameter [57]). The eukaryotic 
cell lines (osteo- and fibro-blasts) investigated in this research are of approximately the same size as $S$. boulardii [58]. Thus, it may be hypothesized that the laser-modified PLLA surfaces of a dozen or so $\mu \mathrm{m}$ in size (please refer to Figure $2 \mathrm{~F}$ ) are too capacious to anchor staphylococcal cells (of $1 \mu \mathrm{m}$ in diameter). In contrast, the laser-modified protrusions may be used by eukaryotic cells to hook and firmly adhere to these surfaces (please refer to Figure 8, bottom of panel A). This ability may be of paramount importance with regard to bone implants exposed to various types of mechanical stress [59].
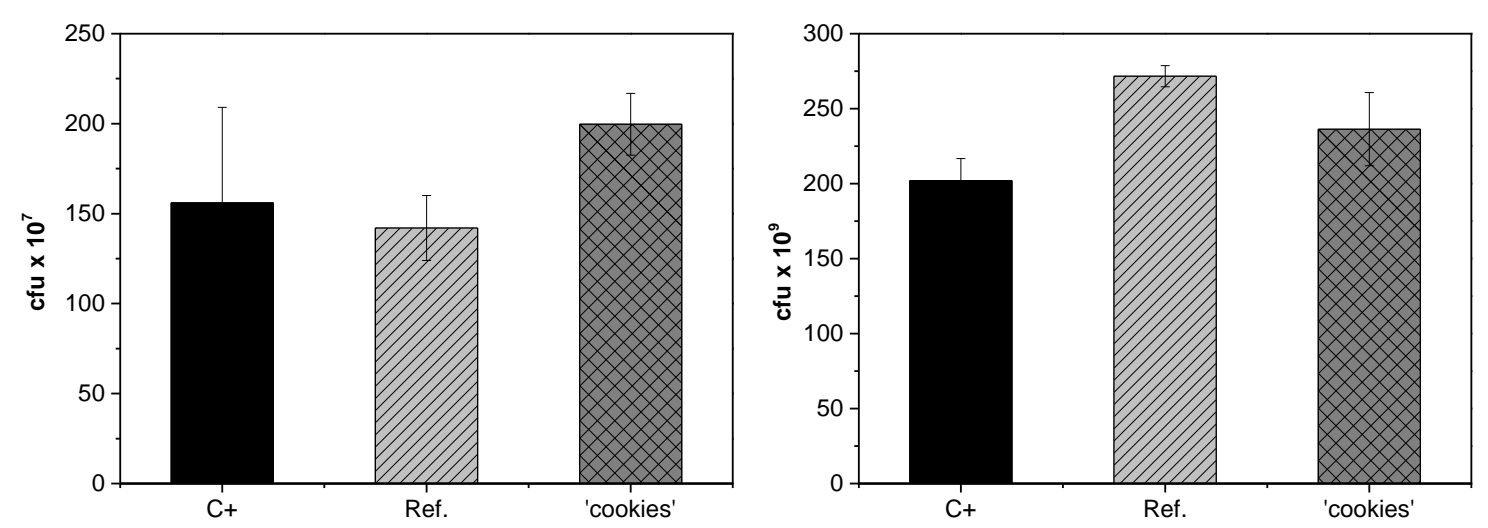

Figure 11. Colonization of analyzed biomaterials by A) biotechnologically-useful fungus S.boulardii and B) pathogenic S.aureus. C+: positive control of growth at the bottom of polystyrene insert.

\section{CONCLUSIONS}

In this article, we presented a new method of femtosecond laser-induced surface modification of biomaterials, with a great potential for tissue engineering applications. The modification carried out allowed us to obtain a micro-sized hierarchical structure on the poly(L-lactide) surface, in the form of evenly distributed round-shaped protrusions. The surface prepared in this way was characterized by greater roughness and better wettability compared to the unmodified one. The irradiated surfaces showed no cytotoxic effect to the osteoblast and fibroblast cell lines. Moreover, the laser modification improved the affinity of both cell types to the PLLA surface, resulting in improved adhesion. A similar trend was observed for eukaryotic fungus, which is used in various branches of biotechnology (S.boulardii). The result was opposite for the pathogenic bacteria S.aureus. We hypothesize that these differences are related to the similar size of eukaryotic cells, which are one order of magnitude larger than the analyzed pathogenic cells of S.aureus. 
The selectivity of the developed method should be emphasized. Our research shows that the selectively modified areas act as a bait for cells, attract them and promote their growth.

\section{Acknowledgment}

The 'Multifunctional biologically active composites for applications in bone regenerative medicine' project is carried out within the TEAM-NET program of the Foundation for Polish Science financed by the European Union under the European Regional Development Fund.

\section{Declaration of interests}

The authors declare that they have no known competing financial interests or personal relationships that could have appeared to influence the work reported in this paper.

\section{REFERENCES}

[1] F.J. O'Brien, Biomaterials \& scaffolds for tissue engineering, Mater. Today. 14 (2011) 88-95. doi:10.1016/S1369-7021(11)70058-X.

[2] K.J. Navare, T. Colombani, M. Rezaeeyazdi, N. Bassous, D. Rana, T. Webster, A. Memic, S.A. Bencherif, Needle - injectable microcomposite cryogel scaffolds with antimicrobial properties, Sci. Rep. (2020) 1-16. doi:10.1038/s41598-02075196-1.

[3] A. Amirsadeghi, A. Jafari, L.J. Eggermont, S.S. Hashemi, S.A. Bencherif, M. Khorram, Vascularization strategies for skin tissue engineering, Biomater. Sci. 8 (2020) 4073-4094. doi:10.1039/d0bm00266f.

[4] G. Turnbull, J. Clarke, F. Picard, P. Riches, L. Jia, F. Han, B. Li, W. Shu, 3D bioactive composite scaffolds for bone tissue engineering, Bioact. Mater. 3 (2018) 278-314. doi:10.1016/j.bioactmat.2017.10.001.

[5] E.M. Benetti, M.K. Gunnewiek, C.A. Van Blitterswijk, G. Julius Vancso, L. Moroni, Mimicking natural cell environments: Design, fabrication and application of bio-chemical gradients on polymeric biomaterial substrates, J. Mater. Chem. B. 4 (2016) 4244-4257. doi:10.1039/c6tb00947f.

[6] P.X. Ma, Biomimetic materials for tissue engineering, Adv. Drug Deliv. Rev. 60 (2008) 184-198. doi:10.1016/j.addr.2007.08.041.

[7] N.R. Richbourg, N.A. Peppas, V.I. Sikavitsas, Tuning the biomimetic behavior of 
scaffolds for regenerative medicine through surface modifications, J. Tissue Eng. Regen. Med. 13 (2019) 1275-1293. doi:10.1002/term.2859.

[8] H. Amani, H. Arzaghi, M. Bayandori, A.S. Dezfuli, H. Pazoki-Toroudi, A. Shafiee, L. Moradi, Controlling Cell Behavior through the Design of Biomaterial Surfaces: A Focus on Surface Modification Techniques, Adv. Mater. Interfaces. 6 (2019) 1900572. doi:10.1002/admi.201900572.

[9] Y. Bu, J. Ma, J. Bei, S. Wang, Surface Modification of Aliphatic Polyester to Enhance Biocompatibility, Front. Bioeng. Biotechnol. 7 (2019) 98. doi:10.3389/fbioe.2019.00098.

[10] M. Alizadeh-Osgouei, Y. Li, C. Wen, A comprehensive review of biodegradable synthetic polymer-ceramic composites and their manufacture for biomedical applications, Bioact. Mater. 4 (2019) 22-36. doi:10.1016/j.bioactmat.2018.11.003.

[11] W. Chen, W. Luo, S. Wang, J. Bei, Synthesis and properties of poly(lactide)poly(ethylene glycol) multiblock copolymers by coupling triblock copolymers, Polym. Adv. Technol. 14 (2003) 245-253. doi:10.1002/pat.301.

[12] A. Smieszek, K. Marycz, K. Szustakiewicz, B. Kryszak, S. Targonska, K. Zawisza, A. Watras, R.J. Wiglusz, New approach to modification of poly (Llactic acid) with nano-hydroxyapatite improving functionality of human adiposederived stromal cells (hASCs) through increased viability and enhanced mitochondrial activity, Mater. Sci. Eng. C. 98 (2019) 213-226. doi:10.1016/j.msec.2018.12.099.

[13] K. Szustakiewicz, M. Gazińska, B. Kryszak, M. Grzymajło, J. Pigłowski, R.J. Wiglusz, M. Okamoto, The influence of hydroxyapatite content on properties of poly(L-lactide)/hydroxyapatite porous scaffolds obtained using thermal induced phase separation technique, Eur. Polym. J. 113 (2019) 313-320. doi:10.1016/j.eurpolymj.2019.01.073.

[14] W. Sun, W. Liu, Z. Wu, H. Chen, Chemical Surface Modification of Polymeric Biomaterials for Biomedical Applications, Macromol. Rapid Commun. 41 (2020) 1-26. doi:10.1002/marc.201900430.

[15] X.H. Wang, D.P. Li, W.J. Wang, Q.L. Feng, F.Z. Cui, Y.X. Xu, X.H. Song, Covalent immobilization of chitosan and heparin on PLGA surface, Int. J. Biol. Macromol. 33 (2003) 95-100. doi:10.1016/S0141-8130(03)00072-2.

[16] K. Szustakiewicz, B. Kryszak, M. Gazińska, J. Chęcmanowski, M. Grzymajło, B. 
Stępak, A.J. Antończak, The effect of selective mineralization of PLLA in simulated body fluid induced by ArF excimer laser irradiation : Tailored composites with potential in bone tissue engineering, Compos. Sci. Technol. 197 (2020) 1-9. doi:10.1016/j.compscitech.2020.108279.

[17] T. Kokubo, H. Takadama, How useful is SBF in predicting in vivo bone bioactivity?, Biomaterials. (2006). doi:10.1016/j.biomaterials.2006.01.017.

[18] C. He, X. Jin, P.X. Ma, Calcium phosphate deposition rate, structure and osteoconductivity on electrospun poly(l-lactic acid) matrix using electrodeposition or simulated body fluid incubation, Acta Biomater. 10 (2014) 419-427. doi:10.1016/j.actbio.2013.08.041.

[19] R. Morent, N. De Geyter, T. Desmet, P. Dubruel, C. Leys, Plasma surface modification of biodegradable polymers: A review, Plasma Process. Polym. 8 (2011) 171-190. doi:10.1002/ppap.201000153.

[20] T. Jacobs, H. Declercq, N. De Geyter, R. Cornelissen, P. Dubruel, C. Leys, A. Beaurain, E. Payen, R. Morent, Plasma surface modification of polylactic acid to promote interaction with fibroblasts, J. Mater. Sci. Mater. Med. 24 (2013) 469478. doi:10.1007/s10856-012-4807-z.

[21] A. Rudolph, M. Teske, S. Illner, V. Kiefel, K. Sternberg, N. Grabow, A. Wree, M. Hovakimyan, Surface modification of biodegradable polymers towards better biocompatibility and lower thrombogenicity, PLoS One. 10 (2015) 1-17. doi:10.1371/journal.pone.0142075.

[22] K. Szustakiewicz, B. Stępak, A.J. Antończak, M. Maj, M. Gazińska, B. Kryszak, J. Pigłowski, Femtosecond laser-induced modification of PLLA/hydroxypatite composite, Polym. Degrad. Stab. 149 (2018) 152-161. doi:10.1016/j.polymdegradstab.2018.01.015.

[23] Y.C. Lim, J. Johnson, Z. Fei, Y. Wu, D.F. Farson, J.J. Lannutti, H.W. Choi, L.J. Lee, Micropatterning and characterization of electrospun poly $(\varepsilon-$ caprolactone)/gelatin nanofiber tissue scaffolds by femtosecond laser ablation for tissue engineering applications, Biotechnol. Bioeng. 108 (2011) 116-126. doi:10.1002/bit.22914.

[24] A. Riveiro, A.L.B. Maçon, J. del Val, R. Comesaña, J. Pou, Laser surface texturing of polymers for biomedical applications, Front. Phys. 5 (2018) 16. doi:10.3389/fphy.2018.00016.

[25] R. Ortiz, I. Aurrekoetxea-Rodríguez, M. Rommel, I. Quintana, M.M. Vivanco, 
J.L. Toca-Herrera, Laser surface microstructuring of a bio-resorbable polymer to anchor stem cells, control adipocyte morphology, and promote osteogenesis, Polymers (Basel). 10 (2018). doi:10.3390/polym10121337.

[26] C.H. Chen, M.Y. Lee, V.B.H. Shyu, Y.C. Chen, C.T. Chen, J.P. Chen, Surface modification of polycaprolactone scaffolds fabricated via selective laser sintering for cartilage tissue engineering, Mater. Sci. Eng. C. 40 (2014) 389-397. doi:10.1016/j.msec.2014.04.029.

[27] C.M. Murphy, F.J. O’Brien, D.G. Little, A. Schindeler, Cell-scaffold interactions in the bone tissue engineering triad, Eur. Cells Mater. 26 (2013) 120-132. doi:10.22203/eCM.v026a09.

[28] T.L. Downing, J. Soto, C. Morez, T. Houssin, A. Fritz, F. Yuan, J. Chu, S. Patel, D. V. Schaffer, S. Li, Biophysical regulation of epigenetic state and cell reprogramming, Nat. Mater. 12 (2013) 1154-1162. doi:10.1038/nmat3777.

[29] F. Chowdhury, S. Na, D. Li, Y.C. Poh, T.S. Tanaka, F. Wang, N. Wang, Material properties of the cell dictate stress-induced spreading and differentiation in embryonic stemcells, Nat. Mater. 9 (2010) 82-88. doi:10.1038/nmat2563.

[30] P.M. Gilbert, K.L. Havenstrite, K.E.G. Magnusson, A. Sacco, N.A. Leonardi, P. Kraft, N.K. Nguyen, S. Thrun, M.P. Lutolf, H.M. Blau, Substrate elasticity regulates skeletal muscle stem cell self-renewal in culture, Science (80-. ). 329 (2010) 1078-1081. doi:10.1126/science.1191035.

[31] Rukmani Sridharan, Investigating biomaterial-based biophysical cues for modulating macrophage polarization towards bone regeneration applications A thesis submitted to the Royal College of Surgeons in Ireland in partial Supervisors :, (2018) 0-216. doi:10.25419/rcsi.10802798.v1.

[32] Y. Han, D. Baltriukienè, E.N. Kozlova, Effect of scaffold properties on adhesion and maintenance of boundary cap neural crest stem cells in vitro, J. Biomed. Mater. Res. - Part A. 108 (2020) 1274-1280. doi:10.1002/jbm.a.36900.

[33] B.L. Bangasser, G.A. Shamsan, C.E. Chan, K.N. Opoku, E. Tüzel, B.W. Schlichtmann, J.A. Kasim, B.J. Fuller, B.R. McCullough, S.S. Rosenfeld, D.J. Odde, Shifting the optimal stiffness for cell migration, Nat. Commun. 8 (2017) 1-10. doi:10.1038/ncomms 15313.

[34] Z. Razinia, P. Castagnino, T. Xu, A. Vázquez-Salgado, E. Puré, R.K. Assoian, Stiffness-dependent motility and proliferation uncoupled by deletion of CD44, Sci. Rep. 7 (2017) 1-10. doi:10.1038/s41598-017-16486-Z. 
[35] J. Sia, P. Yu, D. Srivastava, S. Li, Effect of biophysical cues on reprogramming to cardiomyocytes, Biomaterials. 103 (2016) 1-11.

doi:10.1016/j.biomaterials.2016.06.034.

[36] S.Y. Wong, J. Soto, S. Li, Biophysical regulation of cell reprogramming, Curr. Opin. Chem. Eng. 15 (2017) 95-101. doi:10.1016/j.coche.2017.01.001.

[37] K. Kamguyan, A.A. Katbab, M. Mahmoudi, E. Thormann, S. Zajforoushan Moghaddam, L. Moradi, S. Bonakdar, An engineered cell-imprinted substrate directs osteogenic differentiation in stem cells, Biomater. Sci. 6 (2018) 189-199. doi:10.1039/c7bm00733g.

[38] K. Yang, H. Jung, H.R. Lee, J.S. Lee, S.R. Kim, K.Y. Song, E. Cheong, J. Bang, S.G. Im, S.W. Cho, Multiscale, hierarchically patterned topography for directing human neural stem cells into functional neurons, ACS Nano. 8 (2014) 78097822. doi:10.1021/nn501182f.

[39] Q. Ma, L. Yang, Z. Jiang, Q. Song, M. Xiao, D. Zhang, X. Ma, T. Wen, G. Cheng, Three-Dimensional Stiff Graphene Scaffold on Neural Stem Cells Behavior, ACS Appl. Mater. Interfaces. 8 (2016) 34227-34233. doi:10.1021/acsami.6b12305.

[40] P. Rytlewski, W. Mróz, M. Żenkiewicz, J. Czwartos, B. Budner, Laser induced surface modification of polylactide, J. Mater. Process. Technol. 212 (2012) 1700-1704. doi:10.1016/j.jmatprotec.2012.03.019.

[41] R. Ortiz, I. Aurrekoetxea-Rodríguez, M. Rommel, I. Quintana, M. Vivanco, J. Toca-Herrera, Laser Surface Microstructuring of a Bio-Resorbable Polymer to Anchor Stem Cells, Control Adipocyte Morphology, and Promote Osteogenesis, Polymers (Basel). 10 (2018) 1337. doi:10.3390/polym10121337.

[42] S. Yada, M. Terakawa, Femtosecond laser induced periodic surface structure on poly-L-lactic acid, Opt. Express. 23 (2015) 5694. doi:10.1364/oe.23.005694.

[43] E. Rebollar, M. Castillejo, T.A. Ezquerra, Laser induced periodic surface structures on polymer films: From fundamentals to applications, Eur. Polym. J. 73 (2015) 162-174. doi:10.1016/j.eurpolymj.2015.10.012.

[44] P. Slepička, I. Michaljaničová, P. Sajdl, P. Fitl, V. Švorčík, Surface ablation of PLLA induced by KrF excimer laser, Appl. Surf. Sci. 283 (2013) 438-444. doi:10.1016/j.apsusc.2013.06.127.

[45] B. Kryszak, K. Szustakiewicz, B. Stępak, M. Gazińska, A.J. Antończak, Structural, thermal and mechanical changes in poly(l-lactide)/hydroxyapatite 
composite extruded foils modified by CO2 laser irradiation, Eur. Polym. J. 114 (2019) 57-65. doi:10.1016/j.eurpolymj.2019.02.030.

[46] B. Stępak, M. Gazińska, M. Nejbauer, Y. Stepanenko, A. Antończak, Diverse nature of femtosecond laser ablation of poly(L-lactide) and the influence of filamentation on the polymer crystallization behaviour, Sci. Rep. 9 (2019) 1-12. doi:10.1038/s41598-019-39640-1.

[47] I. Takayama, N. Kondo, S. Kalies, A. Heisterkamp, M. Terakawa, Myoblast adhesion and proliferation on biodegradable polymer films with femtosecond laser-fabricated micro through-holes, J. Biophotonics. 13 (2020). doi:10.1002/jbio.202000037.

[48] G. Ye, W. Wang, D. Fan, P. He, Effects of femtosecond laser micromachining on the surface and substrate properties of poly-lactic acid (PLA), Appl. Surf. Sci. 538 (2021) 148117. doi:10.1016/j.apsusc.2020.148117.

[49] F. Baset, K. Popov, A. Villafranca, J.-M. Guay, Z. Al-Rekabi, A.E. Pelling, L. Ramunno, R. Bhardwaj, Femtosecond laser induced surface swelling in polymethyl methacrylate, Opt. Express. 21 (2013) 12527. doi:10.1364/oe.21.012527.

[50] A.J. Antończak, B.D. Stępak, K. Szustakiewicz, M.R. Wójcik, K.M. Abramski, Degradation of poly(l-lactide) under CO2 laser treatment above the ablation threshold, Polym. Degrad. Stab. 109 (2014) 97-105. doi:10.1016/j.polymdegradstab.2014.07.004.

[51] E. Meaurio, N. López-Rodríguez, J.R. Sarasua, Infrared spectrum of poly(Llactide): Application to crystallinity studies, Macromolecules. 39 (2006) 92919301. doi:10.1021/ma061890r.

[52] K. Szustakiewicz, B. Kryszak, P. Dzienny, V. Hoppe, P. Szymczyk-zi, W. Tylus, M. Grzymajło, Cytotoxicity Study of UV-Laser-Irradiated PLLA Surfaces Subjected to Bio-Ceramisation: A New Way towards Implant Surface Modification, (2021) 1-17.

[53] C.H. Tsou, W.H. Yao, Y.C. Lu, C.Y. Tsou, C.S. Wu, J. Chen, R.Y. Wang, C.C. Su, W.S. Hung, M. De Guzman, M.C. Suen, Antibacterial property and cytotoxicity of a poly(lactic acid)/nanosilver-doped multiwall carbon nanotube nanocomposite, Polymers (Basel). 9 (2017). doi:10.3390/polym9030100.

[54] Y. Wan, C. Wu, G. Xiong, G. Zuo, J. Jin, K. Ren, Y. Zhu, Z. Wang, H. Luo, Mechanical properties and cytotoxicity of nanoplate-like hydroxyapatite/polylactide nanocomposites prepared by intercalation technique, 
J. Mech. Behav. Biomed. Mater. 47 (2015) 29-37.

doi:10.1016/j.jmbbm.2015.03.009.

[55] J.R. Sarasua, N. López-Rodríguez, E. Zuza, S. Petisco, B. Castro, M. Del Olmo, T. Palomares, A. Alonso-Varona, Crystallinity assessment and in vitro cytotoxicity of polylactide scaffolds for biomedical applications, J. Mater. Sci. Mater. Med. 22 (2011) 2513-2523. doi:10.1007/s10856-011-4425-1.

[56] G. Lesage, H. Bussey, Cell Wall Assembly in Saccharomyces cerevisiae, Microbiol. Mol. Biol. Rev. 70 (2006) 317-343. doi:10.1128/mmbr.00038-05.

[57] B.M. Saraiva, M. Sorg, A.R. Pereira, M.J. Ferreira, L.C. Caulat, N.T. Reichmann, M.G. Pinho, Reassessment of the distinctive geometry of Staphylococcus aureus cell division, Nat. Commun. 11 (2020) 1-7. doi:10.1038/s41467-020-17940-9.

[58] R.A. Freitas, J. All, R. Reserved, Nanomedicine, Volume I : Basic Capabilities Nanomedicine, Volume I : Basic Capabilities, Landes Bioscience, Georgetown, 1999. http://www.nanomedicine.com/NMI/8.5.1.htm.

[59] M. Ikar, T. Grobecker-Karl, C. Steiner, Mechanical Stress during implant surgery and its effects on marginal bone: a literature review., Quintessence Int. (Berl). 51 (2020) 142-150. doi:10.3290/j.qi.a43664. 